effective on January 14, 1936. The ratified articles have therefore come into force in all the African territories of Great Britain, Belgium, Egypt, the Anglo-Egyptian Sudan and the Union of South Africa (Science Service, Washington, D.C.). As a result, gorilla, okapi, white rhinoceros, pigmy hippopotamus and eighteen other rare wild animals, together with the unique plant of the Kalahari Desert, Welwitschia, are now absolutely protected. Protection almost as complete is afforded to a series of animals in List A, which may not be killed for ordinary purposes at all, either by natives or whites, but may be taken in strictly limited numbers, with Government permission, for important scientific purposes. There are included such African elephants as possess tusks less than ten pounds in weight. If the tusks be heavier than ten pounds, the elephants fall into Class B, where they are partnered by black rhinoceros, the two species of giraffe, the wild ostrich and several kinds of egrets and hornbills. Class B animals may be hunted only by special licence, whereby the area, time and extent of the hunting is strictly limited and defined.

\section{British Empire Naturalists' Association}

AT the annual general meeting of the British Empire Naturalists' Association to take place in the Artworkers' Guild Hall, London, on April 29, under the chairmanship of Mr. Richard Morse, the lecturer will be Mr. D. Seth-Smith, curator of birds at the London Zoological Gardens. The Council of the B.E.N.A. has recently drawn up a resolution protesting against the choice by the Air Ministry of a section of the Northumberland coast near the Farnes, frequented by many uncommon birds and including the only English breeding station of the eider duck and the only East England breeding station of the grey seal, for a future bombing station. A new local branch for Shropshire has recently been formed by the Association, and has already begun activities. It has been decided to hold the annual B.E.N.A. allnight ramble and dawn bird song record in Surrey on the night of Saturday-Sunday, May 23-24, the organisation of this being carried out by Mr. W. J. Finnigan, who has cared for the previous all-night meetings. The B.E.N.A. herbarium, for long at Bexhill, has now been transferred to the South London Botanical Institute, 323 Norwood Road, London, S.E.24, where it may be inspected daily from 2 until 9 p.m. except on Thursdays, Sundays and days of outings of the Institute.

\section{Electric Developments in British Ships}

DURING the last three years, the shipowning and shipbuilding industries have been seriously depressed. It is satisfactory therefore to learn from a paper by Colonel A. P. Pyne (J. Inst. Elec. Eng., February) that steady progress has been made in the applications of electricity in British ships. The popularity of short cruises in large luxury liners has favoured development. The problem of ventilation has attracted attention. It is now recognised that the stirring up of air by means of fans, or even the delivery of warmed or cooled air to given points by means of ducts, does not suffice. Air conditioning now takes into consideration the problems of the draughtless delivery of purified air and the extraction of vitiated air in the proper proportions. The incoming air must have the right temperature and the correct humidity to suit the climatic conditions of the moment. The air conditioning plant now changes the supply to warmed or cooled air automatically as required. The electric heating of public rooms and cabins is becoming universal. The heaters adopted are generally of the convector type, made more cheerful by luminous effects. The depression of the industry has prevented electric marine propulsion from making much progress. Two large motorships, the Stirling Castle and the Athlone Castle, each having a tonnage of 25,500 and auxiliary generators of 3,500 kilowatts for lighting and power, are at present being built. The Queen Mary, having a tonnage of 73,000 , has auxiliary generators of 9,100 kilowatts capacity. The steam turbo-electric Normandie built in France last year has a tonnage of 75,000 and auxiliary generators for lighting and power of 13,200 kilowatts.

\section{New Telephoto Systems in the United States}

There are various methods now in use in different countries for transmitting photographs, printed matter and line drawings by means of telegraph or telephone wires or by radio. In certain respects the circuits must meet more stringent requirements than those used by speech or music. The sending apparatus scans the picture in closely spaced lines and converts the light and dark portions into electric currents proportional in strength to the light and shade of the picture. The transmission along the line causes a weakening of the current, but this is got over by amplification at the receiver. In a circuit for tele. photography the successive portions of the signal are spread out side by side so that all are seen by the eye at the same time. In telephoning, the ear hears them one after the other and any slight blurring is scarcely noticed. Any little irregularity in the time sequence of the signals is at once seen in the telephotograph and remains as a permanent record. In the Bell Laboratories Record of February, P. Mertz describes how this defect can be remedied by equalising the 'time delay' of the signals (which is done in the new Western Electric telephotograph system). For good pictures this time delay of the various rays in the transmission band must not exceed the twothousandth part of a second. Photographs are given showing the great improvement produced by using this device on the transmission line. It is also shown how 'random noise', telegraph interference, highfrequency noise and 'echo' distort the photograph. The first of the new telephoto systems to be installed connects Miami, Washington, New York, Boston, Chicago, San Francisco, etc., and includes 7,400 miles of main circuit. In a single connexion between sender and receiver, there may be as much as 3,500 miles of cable and 2,500 miles of open wire. 